\title{
GRINDELIA RUPESTRIS A. BARTOLI, TORTOSA \& MARCHESI (ASTERACEAE-ASTEREAE), NOVA CITAÇÃO PARA O RIO GRANDE DO SUL ${ }^{\prime}$
}

\author{
ANABELA SILVEIRA DE OLIVEIRA² LEONARDO PAZ DEBLE ${ }^{3}$ \\ JOSÉ NEWTON CARDOSO MARCHIORI ${ }^{4}$
}

\section{RESUMO}

A espécie é descrita e ilustrada, tem sua distribuição geográfica representada em mapa e é presentemente distinguida de Grindelia buphthalmoides DC., mediante chave dicotômica.

Palavras-chave: Grindelia rupestris, Asteraceae, Astereae.

\section{ABSTRACT}

The species is here described, illustrated and has its geographical distribution represented in map; it is also set apart from Grindelia buphthalmoides DC., by a dichotomous key.

Key words: Grindelia rupestris, Asteraceae, Astereae.

\section{INTRODUÇÃO}

Durante a revisão do gênero Grindelia Willd. no Brasil foi possivel confirmar a ocorrência de Grindelia rupestris A. Bartoli, Tortosa \& Marchesi para a flora sul-rio-grandense.

Bastante rara, a espécie era somente conhecida pelo material-tipo, coletado em barrancos rochosos na localidade de "Quebrada de los Cuervos", no departamento uruguaio de Treinta y Tres (Bartoli, Tortosa \& Marchesi, 1996). No Rio Grande do Sul, sua presença foi assinalada em morros areníticos de Gravataí e São Leopoldo (Figura 2); as poucas coletas conhecidas, até o momento, constam na lista de material examinado.

Grindelia rupestris A. Bartoli, Tortosa \& Marchesi apresenta afinidade com Grindelia buphthalmoides DC., da qual difere pelo porte, pelo tamanho das folhas, pelos capítulos distintamente menores, bem como pela forma e dimensão dos aquênios. As duas espécies podem ser separadas pela seguinte chave dicotômica: 1a. Subarbusto de até $60 \mathrm{~cm}$ de altura. Folhas de 1,5-3,5 cm de comprimento por $0,5-1,5 \mathrm{~cm}$ de largura. Capítulos de 3-4 cm de diâmetro. Invólucro de 6-10 $\mathrm{mm}$ de altura. Flores do disco, de 4-5 mm de comprimento. Aquênios prismáticos, de 3-3,5 $\mathrm{mm}$ de comprimento.

...G. rupestris

1b. Subarbusto de até $2 \mathrm{~m}$ de altura. Folhas de 4-8 $\mathrm{cm}$ de comprimento por 1-2 $\mathrm{cm}$ de largura. Capítulos de 4-6 cm de diâmetro. Invólucro de $12-16 \mathrm{~mm}$ de altura. Flores do disco, de 6-7 mm de comprimento. Aquênios ovados, de $5-7 \mathrm{~mm}$ de comprimento.

..G. buphthalmoides

DESCRIÇÃO DE GRINDELIA RUPESTRISA. BARTOLI, TORTOSA \& MARCHESI

Brittonia, v. 48, n.1, p. 77-78, 1996.

Subarbusto de até $60 \mathrm{~cm}$ de altura, com ramos eretos ou ascendentes, folhosos até o ápice e terminados em capítulo séssil (Figura 1a). Fo-

1 Artigo recebido em 21/3/2005 e aceito em 7/4/2005.

2 Bióloga, Msc., Doutoranda do Curso de Pós-graduação em Engenharia Florestal, Centro de Ciências Rurais, Universidade Federal de Santa Maria, CEP 97105-900, Santa Maria (RS).anabela.biol@mail.ufsm.br

3 Biólogo, Msc., Doutorando do Curso de Pós-graduação em Engenharia Florestal, Centro de Ciências Rurais, Universidade Federal de Santa Maria, CEP 97105-900, Santa Maria (RS).deble.biol@bol.com.br

4 Engenheiro Florestal, Dr., Professor Titular do Departamento de Ciências Florestais, Centro de Ciências Rurais, Universidade Federal de Santa Maria, CEP 97105-900, Santa Maria (RS).balduinia@mail.ufsm.br 


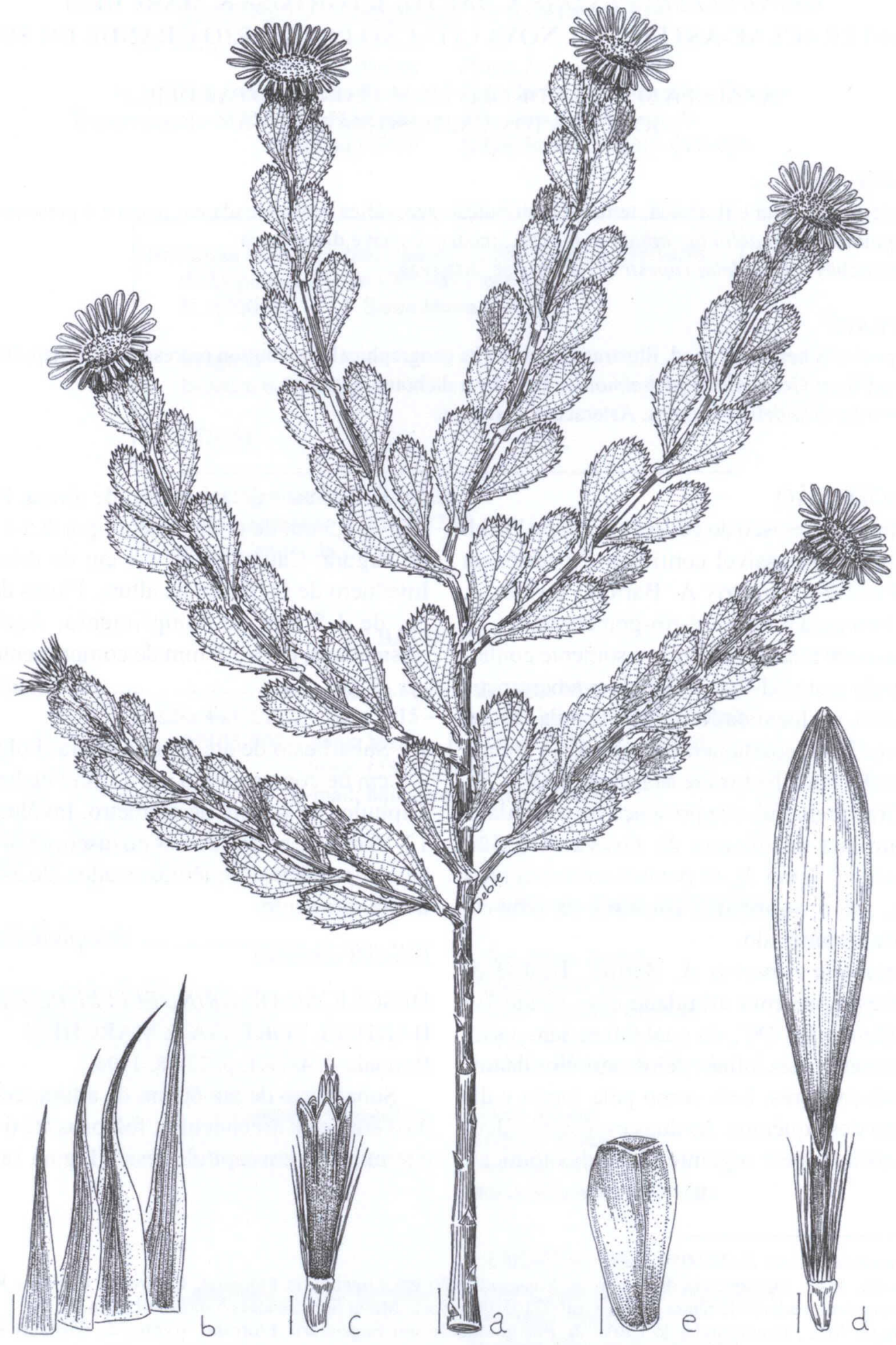

FIGURA 1 - Ramo de Grindelia rupestris (a). Brácteas involucrais (b). Flor do disco (c). Flor ligulada (d). Aquênio (e). Escala $a=1 \mathrm{~cm} ; \mathrm{b}, \mathrm{c}, \mathrm{d}, \mathrm{e}=1 \mathrm{~mm}$. 


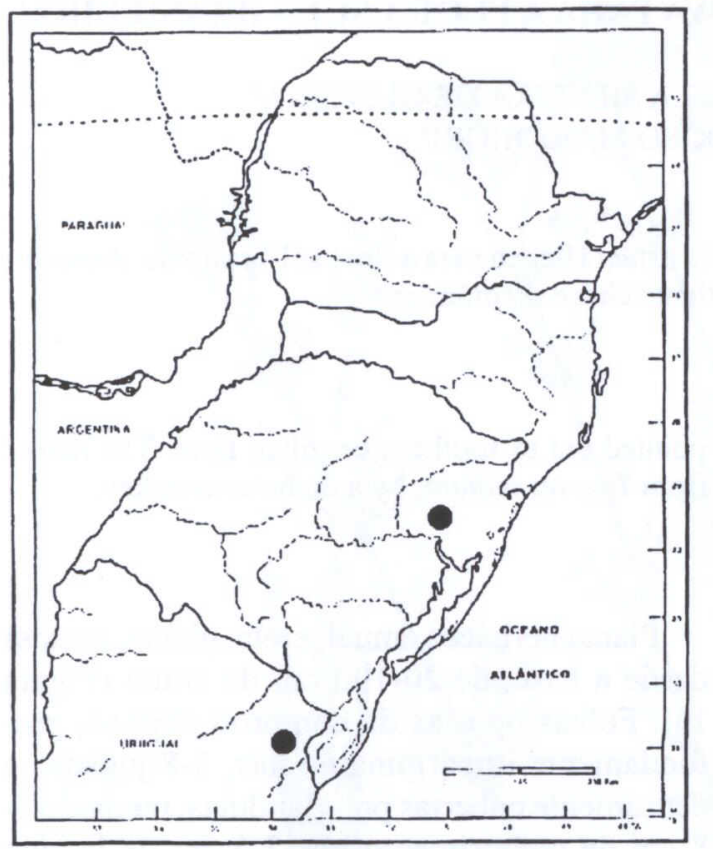

FIGURA 2 - Mapa de ocorrência de Grindelia rupestris A. Bartoli, Tortosa \& Marchesi.

lhas de 1,5-3,5 cm de comprimento por 0,5-1,5 $\mathrm{cm}$ de largura, alternas, sésseis, glabras ou com escassos pêlos glandulares, oblongas até obovadas, agudas ou obtusas no ápice e com margens serradas ou dentadas (Figura 1a). Capítulos de 3-4 $\mathrm{cm}$ de diâmetro, sésseis ou subsésseis, dispostos no ápice dos ramos. Invólucro de $6-10 \mathrm{~mm}$ de altura por $10-15 \mathrm{~mm}$ de diâmetro, composto por 8 séries de filárias pontuado-glandulosas; as externas, lineares, de 6-8 $\mathrm{mm}$ de comprimento por $0,7-1 \mathrm{~mm}$ de largura; as internas, lanceoladas, de $8-9 \mathrm{~mm}$ de comprimento por 1,5-2 mm de largura (Figura 1b). Flores liguladas em número de 20-30 por capítulo, com corola de $15-18 \mathrm{~mm}$ de comprimento por 2-3 mm de largura (Figura 1d). Flores tubulosas (cerca de 100 por capítulo), com corola de $5 \mathrm{~mm}$ de comprimento (Figura 1c). Pápus formado por 15-18 aristas desiguais, de 3-4,5 mm de comprimento, ciliadas na margem. Aquênios prismáticos, de 3-3,5 $\mathrm{mm}$ de comprimento por $2 \mathrm{~mm}$ de largura (Figura 1e).

TIPO: Uruguai. Dpto. Treinta y Tres, Quebrada de los Cuervos, Bayce et al. s.n., 24.IX.1993 (MVFA 22.288!)

\section{Material examinado}

BRASIL: RIO GRANDE DO SUL: Gravataí, morro Itacolomi, arbusto em campo pedregoso, no topo do tabuleiro, capítulos amarelos, $\mathrm{M}$. Sobral, X.1986 (ICN 85.323). São Leopoldo, in summo, monte das Cabras, in rupestribus dumetosis, B. Rambo, 07.XII.1948 (PACA 38.614); ibidem, B. Rambo, 31.X.1944 (PACA 1.748).

URUGUAI: TREINTA Y TRES: Quebrada de los Cuervos, ladera alta, pedregoso, flor amarela, 24.IX.1993, D. Bayce, G. Speroni, I. Grela (MVFA 22.288).

\section{AGRADECIMENTOS}

Os autores agradecem a Maria Salete Marchioretto e a Paulo Brack, curadores dos Herbários PACA e ICN, pelo empréstimo de exsicatas, bem como a Ana González, do Herbário MVFA, pelo acesso ao tipo de Grindelia rupestris.

\section{BIBLIOGRAFIA}

Bartoli, A., R. D. Tortosa \& G. H. Rua. Una nueva especie de Grindelia (Asteraceae) de Uruguay. Hickenia, San Isidro, n. 26, p. 119-122, 1995.

Bartoli, A., R. D. Tortosa \& E. Marchesi. Two new species of Grindelia (Astereae, Asteraceae) from Uruguay. Brittonia, n. 48, p. 75-78, 1996.

Bartoli, A., R. D. Tortosa. Revisión de las especies sudamericanas de Grindelia (Asteraceae: Astereae). Kurtziana, Cordoba, v. 27, p. 327359, 1999.

Cabrera, A. L. Revisión de las especies sudamericanas del género Grindelia. Rev. Mus. La Plata, n. 33, p. 207-249, 1931. 